International Review of Research in Open and Distributed Learning Volume 17, Number 2

February - 2016

\title{
Should Instructors Require Discussion in Online Courses? Effects of Online Discussion on Community of Inquiry, Learner Time, Satisfaction, and Achievement
}

Moon-Heum Cho and Scott Tobias

Sungkyunkwan University, South Korea, Kent State University at Stark, United States

\begin{abstract}
Online discussion is a commonly used means to promote student understanding of a topic and to facilitate social interaction among students or between students and instructor; however, its effects on student learning in online learning environments have rarely been investigated. The purpose of this study was to examine the role of online discussion in student learning experiences measured with community of inquiry, learner time, satisfaction, and achievement. One instructor taught the same online course for three consecutive semesters using three different conditions. During one semester enrolled students engaged in no discussion, during another semester they engaged in discussion without instructor participation, and in the remaining semester they engaged in discussion with active instructor participation. No significant differences were found among conditions in cognitive presence and the instructor's teaching presence, whereas significant difference was found in social presence among conditions. No significant differences among conditions were found time spent on Blackboard, course satisfaction, and student achievement. Implications for online teaching and learning as well as for designing an online course conclude the paper.
\end{abstract}

Keywords: online discussion, learner time, instructor involvement in discussion, community of inquiry, online interaction, satisfaction. 


\section{Introduction}

Many researchers have agreed that discussion in online classes enhances student learning and facilitates social interaction (An, Shin, \& Lim, 2009; Andresen, 2009; Hew \& Cheung, 2013; Hrastinski, 2008). Online discussion also creates opportunities to enhance student learning through collaboration (Palmer, Holt, \& Bray, 2008; Hew \& Cheung, 2013). Specifically, the nature of discussion allows each student equal opportunity to participate in and create collective knowledge by sharing and elaborating ideas. Through collaborative knowledge-building processes, each student becomes reflective, thinks critically, and understands concepts better than if she or he were studying alone (Hew \& Cheung, 2013).

Discussion not only supports learning but also facilitates social interaction among students (Andresen, 2009; Kehrwald, 2008; Swan \& Shih, 2005). Through social interaction in online discussion, students share task-related messages, such as concern about the difficulty of a task, progress on a task, support of others' learning processes, and their own strategies for completing a task. In addition, students share messages unrelated to tasks, including humor or thoughts about daily life. In an online learning environment where students feel isolated or lonely, social interaction through discussion helps online students feel connected to others (So \& Brush, 2008; Swan \& Shih, 2005).

When students are given these learning and social opportunities via online discussion, they are expected to develop a sense of a learning community as a positive sense of community essentially contributes to their course satisfaction (Swan \& Shih, 2005), perceived learning (Richardson \& Swan, 2003), and social presence (Kehrwald, 2008). Because the effects of online discussion have been reported overall as positive with regard to student learning, many online instructors feel obligated to include discussion as a part of learning activities in their online courses (Cho \& Summers, 2012; Davies \& Graff, 2005; Palmer et al., 2008).

Many of these studies, however, were based on correlation analyses such as regression and were conducted without control and experimental groups. Although regression studies have shown relationships among variables, the effects of discussion in the experimental situations were not investigated thoroughly. In this study we sought to examine the extent to which the online instructors should involve themselves in discussion, if at all, to enhance students' online learning experiences. We viewed students' online learning experiences in terms of multiple aspects, including community of inquiry (CoI), learner time, course satisfaction, and student achievement.

\section{Online Discussion and the Community of Inquiry}

Online discussion provides opportunities for students and instructors to form a virtual community of inquiry (CoI; Akyol, Vaughan, \& Garrison, 2011; Arbaugh et al., 2008; Garrison \& Arbaugh, 2007; Kozan \& Richardson, 2014). Through active online interaction students and instructors co-create a CoI comprising three overlapping presences, including a social, cognitive, and teaching presence. Students' deep learning occurs when the three types of presence interact in online learning contexts (Akyol et al., 2011). Social presence refers to "the ability of participants to identify with the community (e.g., course of study), communicate purposefully in a trusting environment, and develop interpersonal relationships by 
way of projecting their individual personalities" (Garrison, 2009, p. 352). In online discussion, students not only interact socially but also support and encourage each one's critical and higher order thinking (Garrison \& Akyol, 2013). Cognitive presence refers to students' ability to construct and validate meaning through continuous reflection and conversation in online learning environments (Akyol et al., 2011; Garrison, Anderson, \& Archer, 2001; Kozan \& Richardson, 2014). Online discussion provides opportunities for students to engage in the learning process deliberately and proactively by interacting with other students (Kozan \& Richardson, 2014). Through discussion, students can identify issues or problems, explore solutions, integrate them, and resolve the issues. Active cognitive presence enhances students' learning. Teaching presence refers to the teacher's ability to design, facilitate, and direct cognitive and social process to realize meaningful learning outcomes (Anderson, Rourke, Garrison, \& Archer, 2001). In online discussion, teachers promote and facilitate the discussion so that students engage in deep social and cognitive presence; therefore, the instructor's role as a facilitator is critical in online discussion (Arbaugh et al., 2008; Garrison \& Arbaugh, 2007).

\section{Online Discussions and Time Dedication}

Online discussion requires both students and instructors to dedicate a significant portion of their time to participation. Although very little empirical research has been conducted, one may reasonably assume that posting initial messages, reading others' messages, and replying to others' messages take time. If students actively participate in discussion or are visibly active by posting many messages, they may spend significant learning time in online discussion. Less visibly active students also spend a significant portion of their learning time with online participation. Beaudoin (2002) found that during the two-week period of online conferences, less visibly active students spent on average 7.6 hours with the online course, read others' comments, and spent another 2.2 hours writing comments for the discussion. Students spent these hours merely for participation in discussion. When one considers time spent on other learning activities, such as reading assignments and completing projects, the amount of time spent for two weeks for an online conference is considerable.

Online instructors also spend a significant portion of their teaching time facilitating discussion. Online researchers and practitioners have recommended that online instructors post at least one message per day, $\log$ in to a discussion board at least once a day, maintain a focused discussion, summarize discussion periodically, encourage students to engage in discussions, and promote students' critical thinking (Rovai, 2007). These suggestions emphasize the deep involvement of instructors in the discussions even if they do not visibly present themselves by posting messages. Ebner and Holzing (2005) found that an online instructor spent significantly more time than students in discussions. Similar research results were also reported in a graduate online course. Davidson-Shivers (2009) found that the online instructor in a graduate course spent a substantial amount of time to facilitate students' learning in online discussion. The instructor kept monitoring discussions even though she minimized her postings by reading and providing suggestions to students' questions. Both online instructors and students spend a significant portion of their time participating in discussion.

\section{Online Discussion and Course Satisfaction}


Course satisfaction is an important variable related to student learning and retention in an online course (Kuo, Walker, Schroder, \& Belland, 2014). Positive relationships between interactivity and course satisfaction were reported in several empirical studies. For example, by administering a survey in 73 online courses, Swan (2001) found that clarity of design, interaction with instructors, and active discussion with other students were significantly associated with students' perceived learning and satisfaction. Swan's study showed that interactivity contributed to the development of CoI, which led to students' perceived learning and course satisfaction. Finding that student-instructor and studentstudent interaction predicted online students' perceived learning and course satisfaction in online learning environments, Sher (2009) asserted that most of the student-instructor and student-student interaction occurs through discussion. In addition, So and Brush (2008) found that collaborative learning through interaction among students is associated with social presence and course satisfaction in online learning. In sum, these empirical studies indicated that the active interaction in online discussion is positively related to students' course satisfaction.

\section{Online Discussion and Achievement}

Online discussions are expected to enhance student learning. Because students collectively create knowledge through online discussion by sharing and elaborating concepts, one may reasonably presume that high interactivity in online discussion enhances student achievement as well (Davies \& Graff, 2005; Palmer et al., 2008). Very few empirical studies have been conducted to examine the effects of online discussion on student achievement; however, the results of these studies showed that online discussion is not necessarily related to student achievement. For example, Davies and Graff (2005) divided undergraduates majoring in business into four groups: high passing grade, medium passing grade, low passing grade, and failed. Then they compared students' interactivity and their final grades. Davies and Graff found no significant relationships in online discussion interactivities among passing students; however, they found failed students tended to interact less with others and concluded that high interactivity in online discussion does not necessarily lead to high performance in online learning environments. Finding similar results, Palmer, Holt, and Bray (2008) identified two significant variables that predicted students' final grades in an undergraduate engineering management course: the number of initial postings and students' prior general academic performance. Interactivity indices, such as the number of messages read and the number of replies to messages, were not significantly associated with student achievement. Palmer et al. determined that some students engaged in deep learning processes while they created initial messages; however, others simply replied and read others' messages without deep learning. More empirical research is necessary to examine whether interactivity in online discussion predicts student achievement in online learning environments.

\section{Purpose of the Study}

Despite the importance of examining the role of discussion in students' online learning experiences, very little empirical research has been conducted with an experimental research design. In the current study, we compared students' learning experiences among three experimental discussion conditions: (a) no discussion, (b) discussion with no instructor participation, and (c) discussion with active instructor participation. The overarching research purpose in this study was to investigate the role of discussion in 
online students' learning experiences, including community of inquiry (Shea \& Bidjerano, 2010), learner time, satisfaction, and achievement. More specific research questions appear below:

1. Does online discussion influence community of inquiry?

2. Does online discussion influence the time students spend on a course management system?

3. Does online discussion influence student satisfaction with the course?

4. Does online discussion influence student achievement?

\section{Method}

\section{Participants}

Students enrolled in three separate sections of a sophomore-level online course participated in this study. The online course was offered by a university located in the Midwestern United States and fully delivered online via Blackboard with no face-to-face meetings. Maximum enrollment in the course was 30. Twentyeight, 25, and 29 students in each section of the course participated in the study; therefore, the research participation rates in each course were $93.3 \%, 83.3 \%$, and $96.7 \%$, respectively. A total of 82 students chose to complete the online questionnaire. The resulting sample $(n=82)$ was predominantly female (89\%) as opposed to male (11\%). The age of the respondents ranged from 19 to 55 years of age, with a mean age of 27.46 years $(S D=8.56)$. The sample comprised four freshmen $(4.9 \%), 20$ sophomores (24.4\%), 29 juniors (35.4\%), and 27 seniors (32.9\%). Two students selected other for their undergraduate standing. Responses indicated that $78.3 \%$ of the sample consisted of individuals who identified as White, 18.1\% as African American, 1.2\% as Asian American, and 2.4\% as other.

\section{Assignment of Course Conditions}

The same instructor provided all students with the same course material at the same teaching pace for three consecutive semesters. The three conditions were as follows:

Condition 1: No online discussion was held in the course during the entire semester.

Condition 2: The instructor posed one discussion topic each week for eight weeks of the semester. Each week students participated in discussion. One initial posting and at least one response were required; however, the instructor never participated in the discussion, which was solely operated by students during the entire semester.

Condition 3: The instructor posed one discussion topic each week for eight weeks. Different from Condition 2, the instructor actively participated in discussions each week, prompting students to elaborate their thoughts, providing comments on students' postings, and summarizing each week's discussion. 
Course design. The course instructor participated in the Quality Matters (QM) training offered by the university before he developed the online course. Then, he designed and developed the course following the QM rubric, which consisted of a set of eight general standards and a total of 43 specific criteria that explain the standards (see https://www.qualitymatters.org/ rubric for more information). Student assignments were presented in a weekly folder that included an overview of the activity, video lectures, and assigned book chapters. Students were evaluated with three exams delivered through Blackboard, six online quizzes, and one critical paper. In addition, regardless of the discussion conditions, students introduced themselves in all classes on a discussion board during the first week, following the guideline of the QM rubric. For the entire semester, students were able to ask questions about course materials, quizzes, or other courses on another discussion board. The only difference between the discussion groups and the control group was whether a class participated in eight discussion boards or not. The topics were related to content covered each week.

\section{Instructor's Teaching Practices}

Regardless of course conditions, the online instructor was available via email. He responded to most student emails within five hours on average during the week. Because the instructor checked emails on his mobile phone, he was able to reply to student email quickly. Grades on the exams and quizzes were posted immediately in the individualized grade book once students completed them. Feedback and grades on individuals' critical papers were provided within a week.

\section{Measures}

Several instruments were used to measure students' online learning experiences. More specific information appears below.

Community of inquiry. We used the community of inquiry instrument developed by Arbaugh et al. (2008). The validity and reliability of the CoI has been demonstrated by numerous researchers (e.g., Arbaugh et al., 2008; Kozen \& Richardson, 2014). The CoI consisted of 34 items measuring three aspects of online learning, including teaching presence $(n=13)$, social presence $(n=9)$, and cognitive presence $(n$ =12). Teaching presence had three subscales: design and organization $(n=4)$, facilitation $(n=6)$, and direct instruction $(n=3)$. Cronbach's alpha with our participants was $.95, .95$, and .93 , respectively. Social presence had three subscales: affective expression $(n=3)$, open communication $(n=3)$, and group cohesion $(n=3)$. Cronbach's alpha with our samples was $.87, .92$, and .78 , respectively. Cognitive presence had four subscales: triggering event $(n=3)$, exploration $(n=3)$, integration $(n=3)$, and resolution $(n=3)$. Cronbach's alpha with our participants was $.91, .78, .93$, and .90, respectively. We used a 7-point Likert scale, in which 1 indicated not at all true of me and 7 indicated very true of me.

Course satisfaction. Three items were used to measure students' course satisfaction from Artino's (2009) study. Cronbach's alpha for course satisfaction was .98. We used a 7-point Likert scale, in which 1 indicated not at all true of me and 7 indicated very true of me. 
Students' time on Blackboard. Students' time spent on an online class was calculated via a course management system-Blackboard in this study. The total amount of time students spent during a semester (16 weeks) online was downloaded from Blackboard and used for data analysis.

Student achievement. Student achievement was calculated with percentiles. For equal comparison students' discussion grades from Conditions 2 and 3 were not included when comparing achievement among conditions.

\section{Procedure}

An online survey was developed to measure students' learning experiences online. At the end of the semester, the survey link was administered as a part of class activity. The instructor posted the link in a weekly folder and encouraged students to participate in the study. Participation in the survey was voluntary and students were neither penalized nor rewarded for their participation in the research survey. The study was approved by the campus Institutional Review Board (IRB) and conducted accordingly.

\section{Results}

\section{Community of Inquiry}

In order to address the first research question-"Does online discussion influence community of inquiry?"-an analysis of variance (ANOVA) was undertaken using the 10 subcomponents of CoI: three subcomponents for teaching presence, including design and organization, facilitation, and direct instruction; three subcomponents for social presence, that is, affective presence, open communication, and group cohesion; four subcomponents for cognitive presence, including triggering event, exploration, integration, and resolution. The mean and standard deviation for these variables appear in Table 1, and results of the ANOVA are presented in Table 2.

Table 1

Mean and Standard Deviation of CoI by Conditions

\begin{tabular}{lccc}
\hline Community of Inquiry & \multicolumn{3}{c}{ Condition } \\
\cline { 2 - 4 } & $\begin{array}{c}\text { No discussion } \\
(n=28)\end{array}$ & $\begin{array}{c}\text { Discussion with no } \\
\text { instructor } \\
\text { participation } \\
(n=25)\end{array}$ & $\begin{array}{c}\text { Discussion with active } \\
\text { instructor } \\
\text { participation } \\
(n=29)\end{array}$ \\
\hline Teaching Presence & $6.23(1.15)$ & $6.01(1.18)$ & $6.39(0.94)$ \\
Design \& organization & $6.39(1.05)$ & $6.08(1.21)$ & $6.52(0.87)$ \\
Facilitation & $6.13(1.21)$ & $5.96(1.19)$ & $6.30(1.00)$ \\
Direct instruction & $6.24(1.14)$ & $6.03(1.14)$ & $6.40(0.93)$ \\
\hline
\end{tabular}




\begin{tabular}{llll}
\hline Social Presence & $3.70(1.88)$ & $4.72(1.58)$ & $4.85(1.59)$ \\
Affective expression & $2.93(1.76)$ & $3.61(1.75)$ & $4.16(1.81)$ \\
Open communication & $4.18(2.00)$ & $5.29(1.34)$ & $5.25(1.51)$ \\
Group cohesion & $3.99(1.90)$ & $5.27(1.61)$ & $5.13(1.43)$ \\
Cognitive Presence & $5.21(1.49)$ & $5.30(1.56)$ & $5.34(1.47)$ \\
Triggering event & $4.68(1.89)$ & $5.24(1.70)$ & $5.15(1.64)$ \\
Exploration & $4.86(1.62)$ & $5.13(1.58)$ & $5.17(1.51)$ \\
Integration & $5.67(1.18)$ & $5.44(1.55)$ & $5.54(1.42)$ \\
Resolution & $5.53(1.27)$ & $5.40(1.41)$ & $5.51(1.30)$ \\
\hline
\end{tabular}

Note. Standard deviations in parentheses. Likert scale anchors ranged from 1 not at all true of me to 7 very true of me.

Table 2

ANOVA Results for Community of Inquiry (CoI) Between Conditions

\begin{tabular}{llrrrrr}
\hline & & Sum of & & & & \\
& & Squares & df & Mean Square & F & Sig. \\
\hline \multirow{2}{*}{ Teaching presence } & Between Groups & 324.302 & 2 & 162.151 & 1.03 & .363 \\
& Within Groups & 12469.222 & 79 & 157.838 & & \\
& Total & 12793.524 & 81 & & & \\
\hline \multirow{2}{*}{ Social presence } & Between Groups & 1796.340 & 2 & 898.170 & 6.48 & \multirow{2}{*}{.002} \\
& Within Groups & 10960.782 & 79 & 138.744 & & \\
& Total & 12757.122 & 81 & & & \\
\hline \multirow{2}{*}{ Cognitive presence } & Between Groups & 34.888 & 2 & 17.444 & .08 & .924 \\
& Within Groups & 17481.307 & 79 & 221.282 & & \\
& Total & 17516.195 & 81 & & & \\
\hline
\end{tabular}

The condition of discussion in the course was used as the between-subjects variable for this analysis. Statistically significant difference was found only for social presence, $F(2,79)=6.48, \mathrm{p}<.01, \eta 2=0.14$, whereas teaching presence, $\mathrm{F}(2,79)=1.03$, ns, and cognitive presence, $\mathrm{F}(2,79)=0.08$, ns, were not significantly different. A post hoc Tukey test was performed to explore how subcomponents of social presence differed depending on discussion conditions. The results of post hoc Tukey tests are presented below.

Affective presence. The affective presence variable was found to be statistically significant, $F$ $(2,79)=4.34, p=.016, \eta^{2}=0.10$, indicating that significant differences existed between two or more of the discussion conditions. To explore which discussion conditions were significantly different, a post hoc 
Tukey test was conducted. Results of this analysis showed that the condition of no discussion was significantly different from the condition of discussion with active instructor participation $(p<.05)$. No significant difference, however, was present in no discussion (Condition 1) as opposed to discussion with no instructor participation (Condition 2, $p=n s$ ). The results showed that affective presence from the class with discussion with active instructor participation (Condition 3) were significantly higher than both those with no discussion (Condition 1) and discussion with no instructor participation (Condition 2) in the present sample.

Open communication. The open communication variable was found to be statistically significant, $F(2,79)=4.78, p=.011, \eta^{2}=0.11$, indicating that significant differences existed between two or more of the discussion conditions. To explore which discussion conditions were significantly different, a post hoc Tukey test was conducted. Results of this analysis showed that significant differences existed between no discussion (Condition 1) and discussion with no instructor participation (Condition 2, $p<$ .05). In addition, a significant difference existed between no discussion (Condition 1) and discussion with active instructor participation (Condition $3, p<.05$ ). These results showed that students' perceptions on open communication in both discussion conditions (Condition 2 and 3) were significantly higher than the no discussion condition in the present sample. No significant difference was found between discussion with no instructor participation (Condition 2) and discussion with active instructor participation (Condition 3, $p=n s$ ).

Group cohesion. The group cohesion variable was found to be statistically significant, $F(2,79)$ $=7.32, p=.001, \eta^{2}=0.16$, indicating that significant differences existed between two or more of the discussion conditions. To explore which discussion conditions were significantly different, a post hoc Tukey test was conducted. Results of this analysis showed that significant differences existed between no discussion (Condition 1) and discussion with no instructor participation (Condition 2, $p<.05$ ). In addition, a significant difference existed between no discussion (Condition 1) and discussion with active instructor participation (Condition $3, p<.05$ ). These results showed that both discussion conditions (Condition 2 and 3 ) were significantly higher than no discussion (Condition 1) in the present sample for levels of group cohesion. No significant difference was found between discussion with no instructor participation (Condition 2) and discussion with active instructor participation (Condition $3, p=n s$ ).

\section{Learner Time Spent on Blackboard}

To address the second research question- "Does online discussion influence students' time spent on a course management system?"-an ANOVA was conducted using the amount of total time spent on the course site (Blackboard in this case) as the dependent variable and course discussion conditions as the independent variables. Table 3 presents the mean and standard deviation for Time Spent on Blackboard. Results of the ANOVA showed no significant differences in the amount of total time spent on Blackboard among the discussion conditions, $F(2,79)=0.511, p=n s$ (see Table 4). As a result of the nonsignificant findings, no further analysis of the data was undertaken.

Table 3 
Mean and Standard Deviation of the Amount of Total Time Student Spend on Blackboard, Achievement, and Satisfaction by Conditions

\begin{tabular}{lccc}
\hline Variables & \multicolumn{3}{c}{ Condition } \\
\cline { 2 - 4 } & $\begin{array}{c}\text { No discussion } \\
(n=28)\end{array}$ & $\begin{array}{c}\text { Discussion with no } \\
\text { instructor } \\
\text { participation } \\
(n=25)\end{array}$ & $\begin{array}{c}\text { Discussion with active } \\
\text { instructor participation } \\
(n=29)\end{array}$ \\
\hline $\begin{array}{l}\text { Total amount of time on } \\
\text { Blackboard }\end{array}$ & $22.63(8.45)$ & $20.70(11.54)$ & $20.78(12.70)$ \\
Achievement & $82.58(20.22)$ & $80.12(11.65)$ & $82.74(25.04)$ \\
Satisfaction & $5.99(1.54)$ & $5.95(1.34)$ & $6.34(0.94)$ \\
\hline
\end{tabular}

Note. Units of time, achievement, and satisfaction are, respectively, hour, percentiles, and 7-point Likert scale in which 1 indicated not at all true of me and 7 indicated very true of me.

Table 4

ANOVA Results for Time Spent on Blackboard, Course Satisfaction, and Achievement Between Discussion Conditions

\begin{tabular}{llrrrrr}
\hline & & Sum of & & & \\
& & Squares & df & Mean Square & F & Sig. \\
\hline Time spent on & Between Groups & 148.922 & 2 & 74.461 & .511 & .602 \\
Blackboard & Within Groups & 11507.015 & 79 & 145.658 & & \\
& Total & 11655.936 & 81 & & & \\
\hline \multirow{2}{*}{ Course satisfaction } & Between Groups & 24.088 & 2 & 12.044 & .829 & .440 \\
& Within Groups & 1147.290 & 79 & 14.523 & & \\
& Total & 1171.378 & 81 & & & \\
\hline \multirow{2}{*}{ Achievement } & Between Groups & 278.870 & 2 & 139.435 & .902 & .410 \\
& Within Groups & 13295.021 & 79 & 154.593 & & \\
& Total & 13573.891 & 81 & & & \\
\hline
\end{tabular}

\section{Course Satisfaction}

To examine the third research question-"Does online discussion influence students' course satisfaction?"-an ANOVA was undertaken using course satisfaction as the dependent variable and course discussion conditions as the independent variable. Table 3 presents the mean and standard deviation for course satisfaction. Results of the ANOVA showed no significant differences in course satisfaction among 
the discussion conditions, $F(2,79)=0.829, p=n s$ (see Table 4). As a result of the nonsignificant findings, no further analysis of the data was undertaken.

\section{Achievement}

In order to answerer the fourth research question- "Does online discussion influence students' achievement?"-an ANOVA was undertaken using course achievement as the dependent variable and course discussion conditions as the independent variable. Table 3 presents the mean and standard deviation for course satisfaction. Results of the ANOVA showed no significant differences in student achievement among the discussion conditions, $F(2,79)=0.902, p=n s$ (see Table 4). As a result of the nonsignificant findings, no further analysis of the data was undertaken.

\section{Discussion}

The purpose of the study was to investigate effects of online discussion on students' learning experiences represented with CoI, learner time, satisfaction, and achievement. Three different conditions were used to compare students' learning experiences: (a) no discussion, (b) discussion with no instructor participation, and (c) discussion with active instructor participation. Our research results include the following points. First, interaction through discussion did not contribute significantly to students' perception about CoI. More specifically, teaching presence and cognitive presence were not significantly different among discussion conditions. Even if students has no interaction with classmates or instructor through online discussion, their perceptions about teaching presence and cognitive presence were not statistically lower than in Conditions 2 and 3, in which students had active interactions with classmates or the instructor. An explanation is that learning content in this type of basic course can be achievable without strong instructor presence or cognitive presence. Because students could self-study the content, they didn't need instructors' direct instruction or facilitation or because the content was easily learned by oneself students may not need to engage in knowledge construction process.

However, social presence was significantly different among discussion conditions. More specifically, open communication and group cohesion were statistically higher in both discussion groups (Conditions 2 and 3) than in those with no discussion (Condition 1), whereas affective presence was statistically higher in Condition 3 than in Conditions 1 and 2. The results indicate that active instructor participation in discussion (Condition 3) enhanced all three aspects of students' social presence; however, discussion with no instructor participation (Condition 2) enhanced two aspects of social presence: open communication and group cohesion. The results are consistent from the previous studies in that social interaction with instructors and peers in learning process helped students feel socially connected to others (Andresen, 2009; Kehrwald, 2008; So \& Brush, 2008). In particular, interaction with the instructor seems the most important factor that explain students' social presence in online learning community. The results demonstrated the importance of instructor's role for social presence in online learning environments (An, Shin, \& Lim, 2009; Cho \& Kim, 2013; Hew, Cheung, \& Ng, 2010). 
Second, student-teacher interaction or student-student interaction on discussion boards did not add to a learner's workload. The amount of time students spent on Blackboard was not statistically different among the discussion conditions. The results were different from the previous studies in that students spent significant portion of their time in posting, responding, and reading messages (Beaudoin, 2002). We anticipated that students in discussion groups (Condition 2 and 3) would spend significantly more time because they participated in discussions than students in the group with no discussion (Condition 1); however, students who experienced discussion (Condition 2 and 3) did not spend more time on Blackboard than students in the no discussion condition. Further research investigating how students spend time in Blackboard is necessary. Analyzing log data collected from Blackboard would reveal patterns of students' time spent on activities such as participating in discussions, viewing learning materials, or taking a quiz which may reveal more accurate picture of time spent on Blackboard.

Third, student-teacher interactions or student-student interaction on discussion boards did not contribute to student satisfaction with an online course. We found no significant difference in student satisfaction among discussion conditions. In other words, online instructors' presence in discussion boards did not enhance student satisfaction. In addition, the degree of instructors' presence in online discussions (no presence in Condition 2 as opposed heavy presence in Condition 3) had no impact on student satisfaction. Perhaps one of the reasons is that the instructor was present online although he did not present in discussion boards. Young and Norgard (2006) found that online instructor's timely interaction with students is critical to the formation of an online learning community. Our research demonstrated that as long as the instructor communicated with online students in a timely manner through various ways such as email and Blackboard graded quizzes, students were satisfied with the course and might feel the CoI.

Finally, interaction in online discussion did not explain student achievement. We anticipated that three types of interaction-student-teacher, student-student, and student-content of discussion-would enhance online students' understanding of concepts by allowing them to elaborate ideas, compare their own perspective with those of others, and explain concepts in their own words. Davies and Graff (2005) found similar results: They found no relationships between discussion interactivities and achievement. In addition, the degree of instructor participation in online discussion (not active at all in Condition 2 as opposed to very active in Condition 3) did not significantly influence student achievement. The results imply that without discussion boards and without heavy instructor involvement in discussion boards, students can still perform as well as other students in a condition that instructors heavily facilitate intellectual learning in this type of online course, which emphasized understanding basic concepts.

\section{Implications for Teaching Concepts-Focused Classes Online}

This study demonstrates that online discussion and the degree of instructor participation in discussion did not significantly influence student learning experiences measured with CoI, time spent on Blackboard, satisfaction, and achievement in a basic course. Several implications can be drawn from this study. One is that online instructors can reduce their teaching time by reducing the number of comments they make in discussion or by minimizing their involvement in discussion boards in a basic course. This suggestion, 
however, was made under the assumptions that an online course meets at least the following three conditions.

First, an online class should be well-designed. Despite the fact that the instructor did not participate in online discussion (Condition 2) or did not create discussion activities (Condition 1), student satisfaction and achievement were not significantly lower than in Condition 3, in which the instructor actively participated in discussion. A partial explanation may derive from a well-designed course developed based on the QM rubric. According to researchers, course design is one of the important factors determining student satisfaction and perceived learning (Paechter \& Maier, 2010; Swan, 2001; Young, \& Norgard, 2006). In a survey of 233 online students Young and Norgard (2006) found that a majority of them preferred to have the course consistently structured (92\%) and due dates set (85\%). Paechter and Maier (2010) similarly found that clarity and coherent structure in the online course are powerful predictors of student satisfaction with the course. The online course in our study was organized consistently according to the QM rubric. Class activities and consistent course structures might influence students' perceived teaching presence and cognitive presence.

Second, an online instructor should be present online in various ways, such as course design, email communication, or timely feedback. Regardless of classroom conditions, the online instructor in this study conducted a social activity, in which students got to know each other themselves at the beginning of a semester. In addition, the online instructor was available via email and responded to student email in a few hours; furthermore, the instructor provided feedback on research papers within a week. Students' exams and quiz scores were immediately posted for each individual to see after students finished them. Even though the online instructor was not present on discussion boards in Conditions 1 and 2, students seemed to feel the instructor's teaching presence online.

Third, course objectives should be oriented to enhance basic conceptual understanding. We evaluated student performance with quizzes, exams, and a research paper. The nature of this class did not require much interactions among students or between student and instructor. The tasks in this type of basic concept-oriented class did not require students to interact with others. Under the consistent class structure, students were able to predict course activities and assignments and feel comfortable with the way they learn. By working alone, students were able to accomplish their learning goals.

Another implication is that students may not even need to be required to participate in discussion by instructors designing online courses. Many researchers have found that student participation in online discussion was minimal and not active even if it was required (Fung, 2004; Hew, Cheung, \& Ng, 2010; Khine, Yeap, \& Lok, 2003). Khine, Yeap, and Lok (2003) found that students did not actively interact with others by providing feedback even when participation was required. Fung (2004) found that many students simply posted the messages to meet the minimum criteria. Perhaps one of the reasons may be the time needed to read all of them. The messages were a mixture of both cognitive and social content (Chen \& Wang, 2009). Some students may not feel the necessity to participate in discussion because of social messages unrelated to the tasks at hand. Our study results show that student participation in discussion and the degree of instructor participation had no impact on student achievement, satisfaction, 
and time spent on Blackboard. We suggest that online instructors thoroughly consider the nature of their course before requiring discussion instead of mechanically including it as a mandatory student activity.

\section{Limitations and Future Studies}

The current study has several limitations. Considering them, we anticipate future research possibilities and their direction. One limitation is that this research was conducted only in the type of online course that emphasized understanding basic concepts in a content domain. Typically, higher education students would be required to engage with more sophisticated intellectual processes. Because the data were collected from one type of course, the results may differ in a study of another type of online course that emphasizes analysis, application, and synthesis of concepts through heavy collaboration in a domain area. In a future study, we plan to collect data from a different type of course that emphasizes collaboration among group members or uses a constructivist approach that emphasizes cocreation of knowledge.

Another limitation is that the study heavily relied on quantitative method in a very specific situation. A mixed methods approach should be used in further investigations. For example, researchers can interview research participants about their perceived interactions online as well as conduct content analysis with discussion boards to investigate the level of knowledge students created or patterns of online interactions. Results of such a study would contribute to triangulation of future findings.

\section{Conclusion}

The current study adds to the discussion of distance education methodology in relation to online discussions. Readers may need to be cautious in interpreting the results. Because our study was conducted in a basic course, the results have limitations to generalizing its findings in other online learning courses requiring higher intellectual or 21st century skills such as communication, critical thinking, problem-solving and collaboration. We have pointed out that online discussion had no particular impact on students' online learning experiences in a basic course, but posit that the current findings should be seen as part of a larger conversation about how online courses can best build toward positive student outcomes depending on course nature.

Our findings indicate that in a basic online course discussion did not influence students' learning experiences to any extent as long as the instructor was present online in email, grading, and feedback and an online course is well designed. Given these findings, continued exploration of online course discussion should take place to identify what specific benefits they provide. Our argument in this study should be extended to other educational contexts and should be addressed using diverse research methods. Such a variety of approaches would allow a complex picture of online interactions to emerge for our understanding of online interactions in learning.

In addition, we argue that not all online courses should include discussion as a mandatory learning activity and not all the instructors should necessarily actively participate in discussion. Instead, the 
inclusion of discussion should be decided with the consideration of various factors including teaching philosophy, course content, intended learning outcomes, and learner characteristics. In particular, discussion should be utilized when there is a clear learning objective through their inclusion. We recommend that online instructors cautiously consider the necessity of requiring online discussion when designing and developing an online course.

\section{References}

Akyol, Z., Vaughan, N., \& Garrison, D. R. (2011). The impact of course duration on the development of a community of inquiry. Interactive Learning Environments, 19(3), 231-246. doi: 10.1080/10494820902809147

An, H., Shin, S., \& Lim, K. (2009). The effects of different instructor facilitation approaches on students' interactions during asynchronous online discussions. Computers \& Education, 53, 749-760. doi: 10.1016/j.compedu.2009.04.015

Anderson, T., Rourke, L., Garrison, D. R., \& Archer, W. (2001). Assessing teaching presence in a computer conferencing context. Journal of Asynchronous Learning Network, 5(2), 1-17.

Andresen, M. A. (2009). Asynchronous discussion forums: Success factors, outcomes, assessments, and limitations. Educational Technology \& Society, 12(1), 249-257.

Arbaugh, J. B., Cleveland-Innes, M., Diaz, S. R., Garrison, R., Ice, P., Richardson, J., \& Swan, K. P. (2008). Developing a community of inquiry instrument: Testing a measure of the community of inquiry framework using a multi-institutional sample. Internet and Higher Education, 133-136. doi:10.1016/j.iheduc.2008.06.003

Artino, A. R. (2009). Online learning: Are subjective perceptions of instructional context related to academic success? Internet and Higher Education, 12(3/4), 117-125.

doi:10.1016/j.iheduc.2009.07.003

Beaudoin, M. F. (2002). Learning or lurking? Tracking the "invisible" online student. Internet and Higher Education, 5, 147-155.

Chen, F.-C., \& Wang, T. C. (2009). Social conversation and effective discussion in online group learning. Educational Technology Research \& Development, 57, 587-612. doi:10.1007/s11423-009-9121-1

Cho, M.-H., \& Kim, B. J. (2013). Students' self-regulation for interaction with others in online learning environments. Internet and Higher Education, 17, 69-75. doi:10.1016/j.iheduc.2012.11.001 
Cho, M.-H., \& Summers, J. (2012). Factor validity of the motivated strategies for learning questionnaire (MSLQ) in asynchronous online learning environments (AOLE). Journal of Interactive Learning Research, 23(1), 5-28.

Davidson-Shivers, G. V. (2009). Frequency and types of instructor-interactions in online instruction. Journal of Interactive Online Learning, 8(1), 23-40.

Davies, J., \& Graff, M. (2005). Performance in e-learning: Online participation and student grades. British Journal of Educational Technology, 36(4), 657-663. doi:10.1111/j.14678535.2005.00542.x

Ebner, M., \& Holzinger, A. (2005). Lurking: An underestimated human-computer phenomenon. IEEE Multimedia, 12(4), 70-75. doi:10.1109/MMUL.2005.74

Fung, Y. Y. H. (2004). Collaborative online learning: Interaction patterns and limiting factors. Open Learning, 19(2), 135-149. Doi:10.1080/0268051042000224743

Garrison, D. R. (2009). Communities of inquiry in online learning. In P. L. Rogers, G. A. Berg,J. V. Boettcher, C. Howard, L. Justice, \& K. D. Schenk (Eds.), Encyclopedia of distance learning $\left(2^{\text {nd }}\right.$ ed., pp. 352-355). Hershey, PA: IGI Global.

Garrison, D. R., Anderson, T., \& Archer, W. (2001). Critical thinking, cognitive presence, and computer conferencing in distance education. American Journal of Distance Education, 15(1), 7-23. doi: 10.1080/08923640109527071

Garrison, D. R., \& Akyol, Z. (2013). Toward the development of a metacognition construct for communities of inquiry. Internet and Higher Education, 17, 84-89. doi:10.1016/j.iheduc.2012.11.005

Garrison, D. R., \& Arbaugh, J. B. (2007). Researching the community of inquiry framework: Review, issues, and future directions. Internet and Higher Education, 10, 157-172. doi:10.1016/j.iheduc.2007.04.001

Hew, K. F., \& Cheung, W. S. (2013). Audio-based versus text-based asynchronous online discussion: Two case studies. Instructional Sciences, 41, 365-380. doi: 10.1007/s11251-012-9232-7

Hew, K. F., Cheung, W. S. \& Ng, C. S. L. (2010). Student contribution in asynchronous online discussion: A review of the research and empirical exploration. Instructional Science, 38(6), 571-606. doi: 10.1007/s11251-008-9087-0

Hrastinski, S. (2008). What is online learner participation? A literature review. Computers \& Education, 51, 1755-1765. doi:10.1016/j.compedu.2008.05.005 
Kehrwald, B. (2008). Understanding social presence in text-based online learning environments. Distance Education, 29(1), 89-106. doi:10.1080/01587910802004860

Khine, M. S., Yeap, L. L., \& Lok, A. T. C. (2003). The quality of message ideas, thinking and interaction in an asynchronous CMC environment. Educational Media International, 4O(1/2), 115-125. doi: 10.1080/0952398032000092161

Kozan, K., \& Richardson, J. C. (2014). Interrelationships between and among social, teaching, and cognitive presence. Internet and Higher Education, 21, 68-73. doi:10.1016/j.iheduc.2013.10.007

Kuo, Y.-C., Walker, A. E., Schroder, K. E. E., \& Belland, B. R. (2014). Interaction, internet self-efficacy, and self-regulated learning as predictors of student satisfaction in online education courses. Internet and Higher Education, 20, 35-50. doi:10.1016/j.iheduc.2013.10.001

Paechter, M., \& Maier, B. (2010). Online or face-to-face? Students' experiences and preferences in elearning. Internet and Higher Education, 13(4), 292-297. doi:10.1016/j.iheduc.2010.09.004

Palmer, S., Holt, D., \& Bray, S. (2008). Does the discussion help? The impact of a formally assessed online discussion on final student results. British Journal of Educational Technology, 39(5), 847-858. doi:10.1111/j.1467-8535.2007.00780.x

Richardson, J. C., \& Swan, K. (2003). Examining social presence in online courses in relations to students' perceived learning and satisfaction. Journal of Asynchronous Learning Networks, 7(1), 68-88.

Rovai, A. P. (2007). Facilitating online discussions effectively. Internet and Higher Education, 10, 77-88. doi:10.1016/j.iheduc.2006.10.001

Shea, P., \& Bidjerano, T. (2010). Learning presence: Towards a theory of self-efficacy, self-regulation, and the development of a communities of inquiry in online and blended learning environments. Computers \& Education, 55, 1721-1731. doi:10.1016/j.compedu.2010.07.017

Sher, A. (2009). Assessing the relationship of student-instructor and student-student interaction to student learning and satisfaction in web-based online learning environment. Journal of Interactive Online Learning, 8(2), 102-120.

So, H.-J. \& Brush, T. A. (2008). Student perceptions of collaborative learning, social presence and satisfaction in a blended learning environments: Relationships and critical factors. Computers \& Education, 51(1), 318-336. doi:10.1016/j.compedu.2007.05.009

Swan, K. (2001). Virtual interaction: Design factors affecting student satisfaction and perceived learning in asynchronous online courses. Distance Education, 22(2), 306-331. doi: 10.1080/0158791010220208 
Swan, K., \& Shih, L. F. (2005). On the nature and development of social presence in online course discussions. Journal of Asynchronous Learning Networks, 9(3), 115-136.

Young, A., \& Norgard, C. (2006). Assessing the quality of online course from the students' perspective. Internet and Higher Education, 9, 107-115. doi:10.1016/j.iheduc.2006.03.001

\section{Athabasca \\ University}

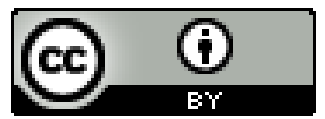

